\title{
Colchicine in ischemic heart disease: the good, the bad and the ugly
}

\author{
Domenico D'Amario ${ }^{1,2}$. Donato Cappetta ${ }^{3}$ - Luigi Cappannoli ${ }^{2}$ - Giuseppe Princi ${ }^{2}$ Stefano Migliaro ${ }^{2}$. \\ Giovanni Diana ${ }^{2} \cdot$ Karim Chouchane ${ }^{2} \cdot$ Josip A. Borovac ${ }^{4}$. Attilio Restivo ${ }^{2}$. Alessandra Arcudi ${ }^{2}$. \\ Antonella De Angelis ${ }^{3} \cdot$ Rocco Vergallo $^{1,2} \cdot$ Rocco A. Montone ${ }^{1} \cdot$ Mattia Galli ${ }^{2,5} \cdot$ Giovanna Liuzzo $^{1,2} \cdot$ Filippo Crea $^{1,2}$
}

Received: 23 January 2021 / Accepted: 22 February 2021 / Published online: 13 March 2021

(c) The Author(s) 2021

\begin{abstract}
Inflammation is the main pathophysiological process involved in atherosclerotic plaque formation, progression, instability, and healing during the evolution of coronary artery disease (CAD). The use of colchicine, a drug used for decades in non-ischemic cardiovascular (CV) diseases and/or systemic inflammatory conditions, stimulated new perspectives on its potential application in patients with CAD. Previous mechanistic and preclinical studies revealed anti-inflammatory and immunomodulatory effects of colchicine exerted through its principal mechanism of microtubule polymerization inhibition, however, other pleiotropic effects beneficial to the CV system were observed such as inhibition of platelet aggregation and suppression of endothelial proliferation. In randomized double-blinded clinical trials informing our clinical practice, low doses of colchicine were associated with the significant reduction of cardiovascular events in patients with stable CAD and chronic coronary syndrome (CCS) while in patients with a recent acute coronary syndrome (ACS), early initiation of colchicine treatment significantly reduced major adverse CV events (MACE). On the other hand, the safety profile of colchicine and its potential causal relationship to the observed increase in non-CV deaths warrants further investigation. For these reasons, postulates of precision medicine and patient-tailored approach with regards to benefits and harms of colchicine treatment should be employed at all times due to potential toxicity of colchicine as well as the currently unresolved signal of harm concerning non-CV mortality. The main goal of this review is to provide a balanced, critical, and comprehensive evaluation of currently available evidence with respect to colchicine use in the setting of CAD.
\end{abstract}

Keywords Colchicine - Ischemic heart disease - Cardiovascular events · Tailored therapy · Efficacy and safety · Personalized medicine

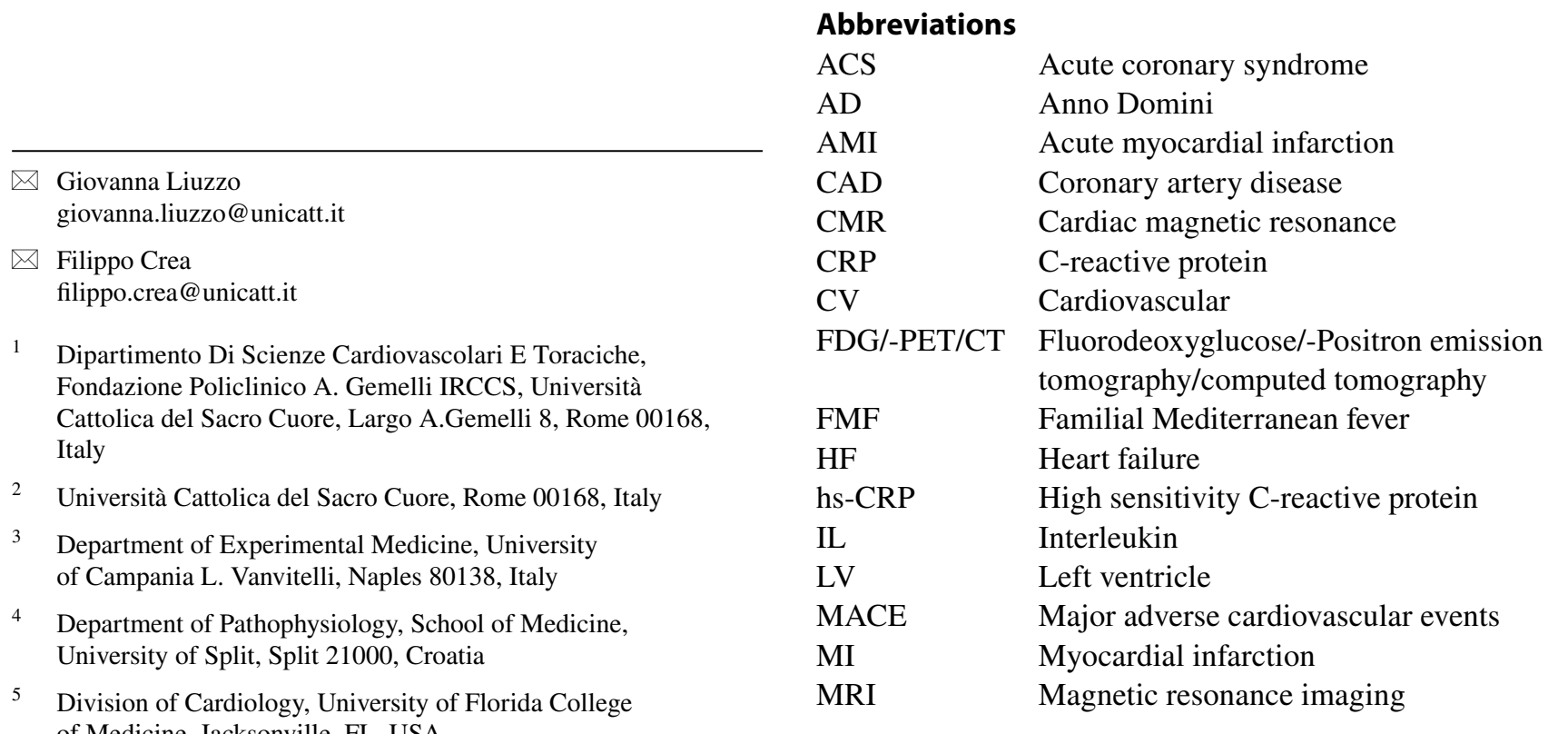




$\begin{array}{ll}\text { NLRP3 } & \text { NLR family pyrin domain containing } 3 \\ \text { NSTEMI } & \text { Non-ST-elevation myocardial infarction } \\ \text { STEMI } & \text { ST-elevation myocardial infarction } \\ \text { TNF } \alpha & \text { Tumor necrosis factor alpha } \\ \text { PCI } & \text { Percutaneous coronary intervention }\end{array}$

\section{Introduction}

Inflammation is the main pathophysiological process involved in atherosclerotic plaque formation, progression, instability, and healing [1, 2]. For decades, a relentless search has been performed to find the most effective strategy to control and/or inhibit inflammatory pathways [3]. Ridker and colleagues, in the landmark CANTOS trial, proved for the first time in a clinical setting the robustness of the inflammatory hypothesis of atherosclerosis, showing that canakinumab, a fully human monoclonal antibody targeting proinflammatory interleukin- $1 \beta$, causes a significant reduction in major adverse cardiovascular (CV) events (MACE) in patients with stable coronary artery disease (CAD) [4]. However, due to the observed increase in the number of deaths related to infections and pharmacoeconomic costeffectiveness limited to high-risk patients only, widespread use of canakinumab did not show uptake in a contemporary clinical practice $[5,6]$.

When various antiinflammatory drugs were tested in the setting of CV disease, a relevant clinical impact in primary and secondary prevention was not achieved [7]. Methotrexate, as tested in the CIRT trial, failed to reduce MACE in patients with diabetes and stable CAD [8] while BI-204, a monoclonal antibody targeting a modified epitope of ApoB100 , did not achieve a reduction in biochemical and imaging markers of inflammation [9]. Darapladib, an inhibitor of Lp-PLA ${ }_{2}$, a phospholipase involved in the production of proinflammatory mediators was found to have no beneficial effect in patients with the acute coronary syndrome (ACS) and established CAD, as demonstrated in the SOLID-TIMI 52 [10] and STABILITY [11] clinical trials. Similarly, in the LATITUDE-TIMI trial, the p38-MAPK-inhibitor losmapimod failed to confer beneficial effects in patients with acute myocardial infarction (AMI) [12] while varespladib tested in ACS, despite its anti-inflammatory effects, actually increased the risk of AMI [13]. Encouraging results seemed to come from tocilizumab, a humanized anti-interleukin-6 receptor (IL-6R) antibody, tested in patients with AMI, but the clear impact on relevant hard end-points still seems far away to come $[14,15]$.

After the long streak of neutral and somewhat disappointing trial results with mostly novel pharmacotherapeutic agents, the idea of using colchicine, an old and well-known antiinflammatory drug, stimulated new research efforts and put it to a test in CV disease prevention [16].

\section{Colchicine: set the stage for a faithful old friend}

Colchicine is a tricyclic lipophilic alkaloid derived from Colchicum autumnale (autumn crocus, meadow saffron) and Gloriosa superba (glory lily) where it is found in corn, seeds, and flowers. Known since antiquity, its use as a medicinal plant to treat joint pain was documented more than 3000-years ago in an old Egyptian medical papyrus, known as the Ebers Papyrus [17]. Later, Byzantine physician Alexander of Tralles recommended in his "Therapeutica" (A.D. 550) the use of colchicum (named hermodactyl or finger of Hermes) as a remedy for gout. Centuries of bad reputation followed, during which the drug was held in low esteem, as it was widely believed that its use was ineffective or even dangerous. There was a turning point in the late seventeenth and early eighteenth century when the use of colchicum in gout was reintroduced in Europe [18]. In 1819, Pelletier and Caventou isolated a substance from the roots of Colchicum autumnale, and in 1833, Geiger purified this substance and gave it the name of colchicine. In 1884, the pharmacist Alfred Houdé improved the purification process by obtaining pure crystallized colchicine compound [19].

\section{Chemistry}

Colchicine is an alkaloid with the formula $\mathrm{C}_{22} \mathrm{H}_{25} \mathrm{NO}_{6}$; the chemical name is $\mathrm{N}-[(7 \mathrm{~S})-5,6,7,9$-tetrahydro- $1,2,3,10$ tetramethoxy-9-oxobenzo(a)heptalen-7-yl)acetamide]. This molecule contains three rings: A-ring which is a trimethoxyphenyl moiety; seven-membered B-ring and C-ring which is a methoxytropone moiety (Fig. 1) [20]. A-ring and C-ring are held in a rigid configuration by B-rings and are highly involved in the binding to tubulin. Colchicoside, a colchicine analogue with a voluminous group in the A-ring, is no longer able to form a complex with tubulin. Similarly, the replacement of C-ring, in lumicolchicine and colchinol, and slight manipulation of the tropolone structure, in isocolchicine, produce inactive compounds with no affinity for tubulin $[21,22]$. On the other hand, significant variations on the B-ring do not prevent colchicine from binding to tubulin but affect the interaction by modulating activation energy of the binding reaction and association/dissociation kinetics $[23,24]$.

\section{Pharmacokinetics}

Colchicine is rapidly absorbed after oral administration and peak plasma concentrations occur within 1-2 h. It has a bioavailability that varies from 24 to $88 \%$ [25]. When released into the bloodstream, more than $40 \%$ is conjugated 


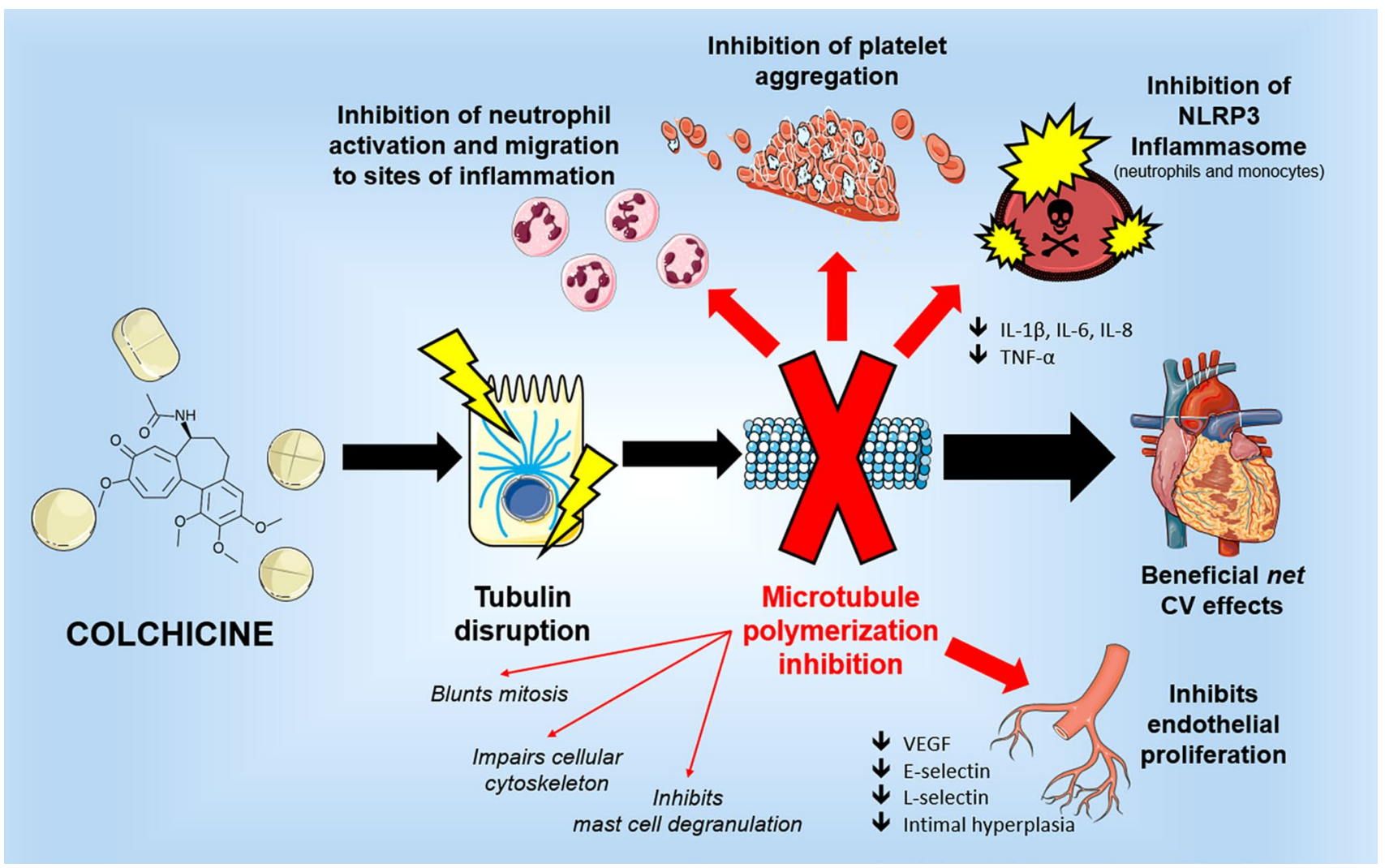

Fig. 1 Colchicine mechanism of action-colchicine primarily causes tubulin disruption and prevents microtubule formation, thus resulting in neutrophils inhibition, antinflammatory effects, beneficial cardio- vascular effects and inhibiting endothelial cells proliferation. $I L$ interleukin; NLRP3 NLR family pyrin domain containing 3; TNF $\alpha$ tumor necrosis factor alpha; $V E G F$ vascular endothelial growth factor to plasmatic proteins and the formation of stable colchicineprotein complexes in many tissues contributes to its large volume distribution $(2.2 \mathrm{~L} / \mathrm{kg})$. Colchicine accumulates in the inflammatory cells, with an intra-leukocyte concentration higher than plasmatic concentration. Although it can cross the placenta and distribute into the breast milk, no clinical impact on the infant's health was observed, likely because of a very low concentration of colchicine in these compartments. Up to $20 \%$ of colchicine is excreted in the urine, while most of the drug undergoes enterohepatic recirculation and is excreted via bile and feces. The average elimination half-life is $20 \mathrm{~h}[26,27]$. Colchicine is a substrate for cytochrome P3A4 (CYP3A4) and P-glycoprotein (P-gp) efflux transporter that are largely responsible for its metabolism and elimination. Colchicine is subjected to extensive first-pass metabolism. Intestinal and hepatic CYP3A4 metabolizes colchicine through oxidative demethylation to 2- and 3-demethylcolchicine. P-glycoprotein extrudes colchicine from the gastrointestinal tract limiting gastrointestinal absorption [28] CYP3A4 and P-glycoprotein are largely responsible for colchicine's drug-drug interactions. Severe adverse interactions have been reported in patients taking colchicine and P-gp inhibitors (e.g. cyclosporine, calcium channel blockers and ranolazine) or CYP3A4 inhibitors (e.g. clarithromycin, fluoxetine, ketoconazole, nefazodone, and cimetidine), resulting in an impaired colchicine metabolism and a consequent elevation in colchicine plasma concentration and toxicity. If this occurs, a colchicine dose reduction is recommended [26]. Moreover, dose adjustment of colchicine is suggested in the elderly population and patients with renal or hepatic impairment [29].

\section{Pharmacodynamics}

The mechanism of action in colchicine is not fully understood. Early studies identified the microtubule as the primary subcellular target. The interaction between colchicine and tubulin depends on temperature, $\mathrm{pH}$ and concentration of tubulin [29, 32]. There is a non-covalent, poorly reversible binding that occurs with a stoichiometry of 1:1 molar ratio of colchicine to tubulin dimer. According to the currently most used model, reversible binding is followed by slow conformational changes that converts the initial complex to a more stable, less easily reversible state [22]. Colchicine binds to tubulin heterodimers impairing spatial conformation, thus causing tubulin disruption and preventing any 
further microtubule growth [30, 31]. Dynamics of microtubule polymerization are essential to cellular functions, such as cell division and migration, intracellular organelle and vesicle transport, and the secretion of cytokines and chemokines [32]. The antimitotic effect against microtubule and spindle formation, although not the only one, is considered the major mechanism by which colchicine intervenes in the molecular processes underlying the inflammation of gout, which remains the most common clinical indication for the use of colchicine.

Colchicine induces down-regulation of multiple inflammatory pathways and the modulation of the innate immunity has most extensively been studied in the clinical context of gout, which is triggered by the deposition of monosodium urate crystals within joints [33]. This process causes an intensive inflammatory response characterized by a massive infiltration of neutrophils, macrophages/monocytes and dendritic cells, resulting in marked tissue injury [34, 35]. While colchicine does not interfere with urate crystal accumulation, it effectively modulates various actions of activated neutrophils that constitute a primary source of immune cells present in the synovial fluid and are pivotal in the generation of crystal-induced acute inflammation. Activated immune cells secrete multiple inflammatory cytokines, including tumor necrosis factor alpha (TNF $\alpha)$, interleukin (IL)- $1 \beta$, IL-6, and IL-8 that, in turn, foster the increased expression of adhesion molecules on the surface of endothelial cells, such as E-selectin, and vascular cell adhesion molecule-1 (VCAM-1) [36]. In addition, urate crystals stimulate the production of superoxide anions from neutrophils necessary for the involvement of the nod-like receptor (NLR) family pyrin domain containing 3 (NLRP3) inflammasome complex that also has a recognized role in inflammatory gout attacks [37,
38]. As mentioned previously, the drug highly concentrates in immune cells where it impairs the secretion of cytokines thus attenuating the inflammatory response [26]. In addition, by modulating E-selectin expression on the surface of endothelial cells, colchicine further reduces neutrophil recruitment and by hampering vesicular trafficking, it is able to decrease both TNF $\alpha$ synthesis in macrophages and TNF $\alpha$ receptor expression in both macrophages and endothelial cells $[30,39,40]$. Yet, disruption of the microtubular network could negatively affect several fundamental cellular processes. Besides the risk of multi-organ toxicity in the case of overdose, there are many known adverse reactions; particularly the most common are gastrointestinal (GI) symptoms including diarrhea, vomiting and nausea, while less common symptoms include myopathy, hematologic disturbances, and muscle weakness. Of note, colchicine may also have a direct toxic effect on cardiomyocytes interfering with its contractile and conduction properties. The main immunomodulatory effects of colchicine are shown in Fig. 1 and summarized in Table 1.

With time, colchicine's therapeutic use was expanded, covering, in addition to gout, diverse conditions such as familial Mediterranean fever (FMF), systemic amyloidosis, pericarditis, atrial fibrillation (AF), scleroderma, Bechet's syndrome, and Sweet's syndrome. Although colchicine is a well-established antiinflammatory agent, mainly used to treat gout and FMF, it has historically demonstrated benefits in a variety of $\mathrm{CV}$ conditions including pericarditis, post-pericardiotomy syndrome, post-procedural AF, and chronic heart failure (HF) while, during the last decade, the investigational focus has shifted to examining the potential benefit of colchicine in CAD [41, 42].

Table 1 Molecular and biological effects of colchicine and clinical implications

\begin{tabular}{lc}
\hline Colchicine mechanisms of action & Clinical implications \\
\hline $\begin{array}{l}\text { Disruption of tubulin and anti-mitotic effect (primary mechanism of } \\
\text { action) }\end{array}$ & $\begin{array}{c}\text { Treatment and prevention of recurrent pericarditis and reduction of } \\
\text { postpericardiotomy syndrome after cardiac surgery } \\
\text { Prevention of atrial fibrillation incidence after cardiac surgery and } \\
\text { recurrence after ablation }\end{array}$ \\
$\begin{array}{l}\text { Inhibition of the NALP3 inflammasome } \\
\text { Enhition of CASPASE-1 and downstream release of IL-1 } \beta\end{array}$ & $\begin{array}{l}\text { Reduction of plaque inflammation, progression and rupture } \\
\text { naive CD4 + lymphocytes }\end{array}$ \\
$\begin{array}{l}\text { Inhibition of macrophages release of ROS, TNF- } \alpha \text {, NO, and IL-1 } \beta \\
\text { Inhibition of neutrophil activation, mobilization, chemotaxis and release } \\
\text { of IL-1 } \beta \text {, IL-8, superoxide, chemotactic factors and L-selectin } \\
\text { Inhibition of intimal hyperplasia and leukocyte VEGF expression in } \\
\text { angioplasty model in dogs }\end{array}$ & $\begin{array}{c}\text { performed acute cardiovascular events and restenosis after PCI is } \\
\text { Inhibition of VEGF expression/release and endothelial proliferation } \\
\text { Reduction of endothelial cells E-selectin expression and neutrophil adhe- } \\
\text { sion inhibition (low doses) }\end{array}$ \\
$\begin{array}{l}\text { Increase of Bcl-2 expression and suppression of Caspase-3 } \\
\text { Inhibition of TGF- } \beta 1 \text { expression }\end{array}$ & $\begin{array}{l}\text { Reduces kidney tubulointerstitial fibrosis } \\
\text { Reduces peritoneal sclerosis }\end{array}$ \\
\hline
\end{tabular}

$B c l$-2 B-cell lymphoma 2; IL interleukin; NALP3 NACHT-LRRPYD-containing protein 3; NO nitric oxide; $R O S$ reactive oxygen species; $T G F$ $\beta 1$ transforming growth factor beta-1; TNF $\alpha$ tumor necrosis factor alpha; $V E G F$ vascular endothelial growth factor 


\section{The good}

In 2013 Nidorf and colleagues [43] conducted the PROBE $L o D o C o$ trial to establish the effectiveness of continuous low-dose colchicine compared to placebo in decreasing the risk of cardiovascular events in patients with angiographically documented stable CAD, showing a reduced risk to develop ACS, cardiac arrest, and ischemic stroke as compared with a placebo. Seven years later Nidorf, with a new and more robust trial-LoDoCo2 $[44,45]$ went on to further investigate the effect that $0.5 \mathrm{mg}$ of colchicine administered daily had on patients with the chronic coronary syndrome (CCS), demonstrating a significant reduction in the composite outcome of cardiovascular death, spontaneous MI, ischemic stroke, or ischemia-driven coronary revascularization (31\% lower relative risk, with a hazard ratio of $0.69,95 \%$ CI $0.57-0.83$ ).

In 2019 with their COLCOT trial Tardif and colleagues [46] assessed the effectiveness of colchicine in preventing major adverse cardiovascular events (MACE) in patients who experienced a recent MI. They showed that using $0.5 \mathrm{mg}$ of colchicine daily significantly reduced the risk of cardiovascular death, MI, stroke, resuscitated cardiac arrest, or urgent hospitalization for unstable angina requiring revascularization during follow-up. Moreover, the effect of time-to-treatment on the primary and secondary efficacy outcomes showed that early initiation of low-dose colchicine within the first 3 days post-MI was associated with a reduction of $48 \%$ in the relative risk of MACE, compared with later initiation, such as on days 4 and 30 . Furthermore, assessment of the in-trial period and lifetime pharmacoeconomic cost-effectiveness of low-dose colchicine treatment compared to placebo in post-MI patients on standard-of-care therapy [47] found that the mean overall per-patient costs were reduced by $47 \%$ for the in-trial and by $69 \%$ for the lifetime period and the incidence of diarrhea was comparable between groups $(9.7 \%$ vs $8.9 \%$ $p=0.35$ ).

Therefore, colchicine proved to reduce cardiovascular events in both acute and chronic CAD settings, i.e., ACS in COLCOT and CCS in LoDoCo2. Although the pathogenic mechanisms underlying these beneficial effects have not been completely elucidated, it might be possible that early administration of colchicine in ACS acts by reducing ischemia-reperfusion damage [48], whereas its administration in patients with CCS promotes plaque stabilization and enhances plaque healing $[49,50]$. Of note, a recent study suggests that low-dose colchicine favorably modifies coronary plaque microstructure, producing a more stable, fibrous plaque phenotype [51].

Other trials supported the use of colchicine in ACS and stable $\mathrm{CAD}$, confirming the pathogenetic role of the inflammation [52-54] and the potential efficacy of colchicine in these clinical scenarios. Of importance, several studies demonstrated an increase of intracardiac production of the inflammasome-specific cytokines IL-1 $\beta$, IL-18, and downstream IL-6 in patients presenting with ACS [55] and that acute colchicine administration was associated with a significant reduction in the transcoronary production of these cytokines [56, 57]. Furthermore, Tucker et al. found that the increased intracoronary levels of two chemokines-CCL2 and CX3CL1, observed in patients with ACS, are effectively suppressed by the colchicine administration [58]. The antiinflammatory properties in the ACS setting were also confirmed by Deftereos et al. [48], showing that in patients with STEMI, the administration of colchicine after diagnostic angiography with a loading dose of $2 \mathrm{mg}$ ( $1.5 \mathrm{mg}+0.5 \mathrm{mg}$ after one hour) followed by $0.5 \mathrm{mg}$ twice daily for 5 days, markedly suppressed levels of biomarkers reflecting post-MI inflammatory response, in particular neutrophil count and C-reactive protein (CRP) that were associated with infarct size, which, in turn, is directly related to prognosis [59]. Furthermore, in the patient subgroup that underwent cardiac magnetic resonance (CMR) imaging in the study from days 6 to 9 after MI, treatment with colchicine was associated with smaller infarct size and reduced biomarker release.

Current ongoing trials are further investigating the role of colchicine in patients with ACS to confirm the beneficial properties of this drug (Table 2). Among those, CLEAR SYNERGY (OASIS 9) is comparing colchicine, spironolactone, and placebo in patients referred for percutaneous coronary intervention (PCI) after STEMI or selected high-risk NSTEMI with the primary aim to evaluate the incidence of cardiovascular death, recurrent myocardial infarction, or stroke [60]. CLEAR SINERGY Neutrophil Substudy [61] is assessing the effect of colchicine on neutrophil activation in STEMI patients. The investigators are examining clinical and genetic factors that determine heterogeneity in response to colchicine treatment. Another ongoing trial is COVERT-MI, which aims to investigate adverse left ventricular (LV) remodeling (primary endpoint, measured by CMR), infarct size, and microvascular obstruction reduction in patients with AMI undergoing PCI treated with colchicine at the time of revascularization and for the following 5 days [62]. The effectiveness of colchicine has also been investigated in patients with heart failure. Accordingly, Deftereos et al. [63] showed that the use of colchicine reduced circulating inflammatory biomarker levels (in particular highsensitivity CRP and IL-6), and had favorable effects on left-ventricular remodeling, although this study failed to demonstrate significant improvement of functional status in patients with $\mathrm{HF}$ and reduced $(<40 \%)$ ejection fraction (EF), namely HFrEF population. 
Table 2 Currently ongoing clinical trials studying colchicine in ischemic heart disease

\begin{tabular}{|c|c|c|c|c|c|}
\hline TRIAL & NCT No & Study design & Clinical setting & Interventions & Outcomes \\
\hline $\begin{array}{l}\text { CLEAR } \\
\text { SYNERGY } \\
\text { (OASIS 9) }\end{array}$ & NCT03048825 & $\begin{array}{l}\text { Randomized, quadruple } \\
\text { blinded, with factorial } \\
\text { assignment }\end{array}$ & $\begin{array}{l}\text { STEMI and high risk } \\
\text { NSTEMI }\end{array}$ & $\begin{array}{l}\text { Colchicine or spironolac- } \\
\text { tone } v s \text {. placebo }\end{array}$ & $\begin{array}{l}\text { Incidence of cardiovascular } \\
\text { death, recurrent myocar- } \\
\text { dial infarction, or stroke }\end{array}$ \\
\hline $\begin{array}{l}\text { CLEAR } \\
\text { SINERGY } \\
\text { Neutrophil } \\
\text { Substudy }\end{array}$ & NCT03874338 & $\begin{array}{l}\text { Observational, prospec- } \\
\text { tive }\end{array}$ & STEMI & Colchicine & $\begin{array}{l}\text { Soluble L-selectin; other } \\
\text { soluble markers of neu- } \\
\text { trophil activity; markers } \\
\text { of systemic inflammation }\end{array}$ \\
\hline COVERT-MI & NCT03156816 & $\begin{array}{l}\text { Randomized, parallel, } \\
\text { quadruple-blinded }\end{array}$ & MI & Colchicine vs. placebo & $\begin{array}{l}\text { Infarct size (at CMR); } \\
\text { LVEF; Microvascular } \\
\text { obstruction }\end{array}$ \\
\hline COPMAN & NCT04139655 & $\begin{array}{l}\text { Randomized, parallel, } \\
\text { triple-blinded }\end{array}$ & $\begin{array}{l}\text { MI and myocardial injury } \\
\text { in non-cardiac surgery }\end{array}$ & $\begin{array}{l}\text { Colchicine } 0.6 \mathrm{mg} / \text { day } v s . \\
\text { placebo }\end{array}$ & $\begin{array}{l}\text { Incidence of Myocardial } \\
\text { Injury after Non- Cardiac } \\
\text { Surgery (MINS); Adverse } \\
\text { Events; infectious compli- } \\
\text { cations }\end{array}$ \\
\hline DRC-04 & NCT03376698 & $\begin{array}{l}\text { Randomized, parallel, } \\
\text { quadruple-blinded }\end{array}$ & T2DM and CAD & $\begin{array}{l}\text { Colchicine } 0.5 \mathrm{mg} / \mathrm{day} \text { or } \\
\text { Colchicine } 0.25 \mathrm{mg} / \text { day } \\
\text { vs. placebo }\end{array}$ & $\begin{array}{l}\text { Change in serum hs-CRP, } \\
\text { FMD, adhesive ability } \\
\text { of white blood cell and } \\
\text { plasma myeloperoxidase } \\
\text { level }\end{array}$ \\
\hline
\end{tabular}

$C A D$ coronary artery disease; $C M R$ cardiac magnetic resonance; FMD flow-mediated dilatation; $h s$ - $C R P$ high sensitive C-reactive protein; $L V E F$ left ventricle ejection fraction; MI myocardial infarction; NSTEMI Non ST Elevation Myocardial Infarction; STEMIST Elevation Myocardial Infarction

\section{The Bad}

\section{Side effects of colchicine in cardiovascular trials and drug interactions}

While the available evidence is globally skewed towards a positive effect of colchicine on ischemic cardiac outcomes, the trade-off between this effect and the risk of adverse reactions (even an increase in the cumulative number of non-cardiovascular deaths) requires further exploration and safety adjudication. Below we discuss adverse reactions reported in some of the major trials. For example, in the COLCOT trial [46], within the colchicine treatment group, $17.5 \%$ of patients had GI-related adverse effects while $0.9 \%$ experienced pneumonia (possibly related to immunosuppressive effects of colchicine). Similarly, GI-related adverse effects were also observed in nearly one-quarter $(23 \%)$ of patients treated in the COPS trial [64], and as much as $7 \%$ of all patients had to discontinue the use of colchicine within 30 days since initiation due to this problem. In the LoDoCo trial [51], $11 \%$ of patients stopped treatment early due to intestinal intolerance and an additional 5\% ended therapy late due to a range of possible side effects. In the LoDoCo2 trial [45], myalgia occurred in $21 \%$ of patients in the colchicine group. In the small-sized COLIN trial [65], ten patients receiving colchicine reported digestive intolerance $(43.4 \%)$ with clinical symptoms of diarrhea, nausea or vomiting and discontinuation of treatment was required for three patients
(13.0\%). Such safety data indicate that the side effects might be an important obstacle to the widespread and more extensive use of this drug in clinical practice. Moreover, it has been reported that combining colchicine with statin treatment might increase the risk of myalgia and, very rarely, acute rhabdomyolysis, especially among patients with renal impairment although literature reports cases of colchicineinduced rhabdomyolysis in patients without renal impairment [66]. In addition to side effects, another element that could hinder a widespread use of colchicine in the setting of $\mathrm{CV}$ disease are the numerous drug-to-drug interactions as summarized in Table 3.

\section{The ugly}

All that glitters is not gold and, as previously elaborated, colchicine does have its ugly side. Unfortunately, not all of the evidence available have in fact fostered enthusiasm about the role of colchicine on cardiovascular events with some major studies yielding neutral or negative results. For instance, the COLIN trial [65] failed to show a reduction in inflammatory and myocardial injury markers as well as beneficial effects on adverse LV remodeling after one month of colchicine administration in patients with STEMI, even if there was a late administration after reperfusion and the loading dose was missed, suggesting that the treatment should be given as soon as possible to reduce reperfusion injuries associated 


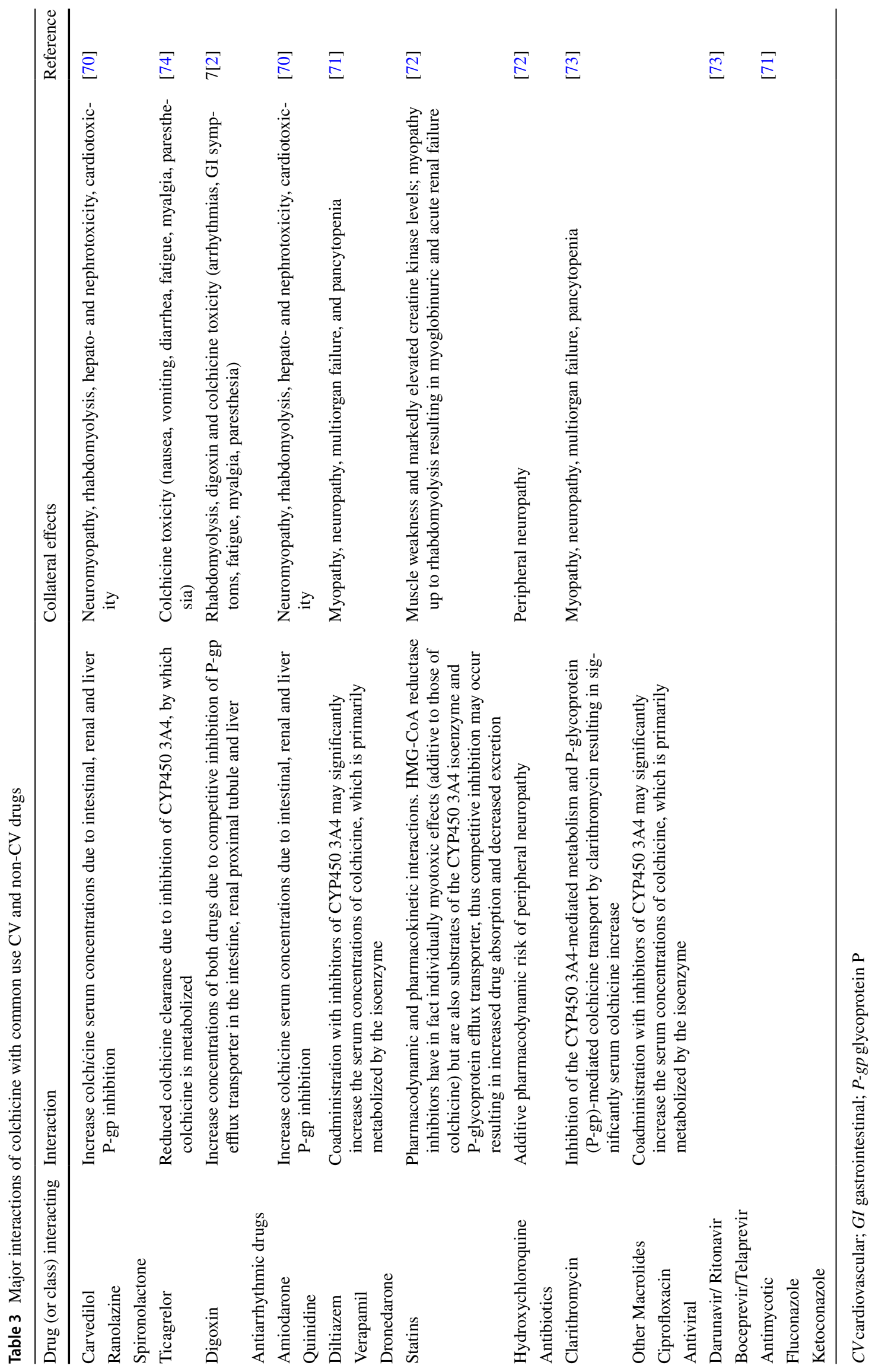


with inflammation burden. A recent systematic review summarizing key trials of colchicine use in ACS concluded that colchicine is likely to reduce MACE in patients with ACS if it is administered for longer than 30 days while it seems to be ineffective if it is administered only pre-procedurally [67]. Furthermore, Tong and colleagues, with their very recent Australian-based COPS trial [64] failed to demonstrate an improvement in cardiovascular outcomes related to the use of colchicine in nearly 800 patients with ACS. The primary endpoint of all-cause mortality, readmission for ACS, ischemia-driven urgent revascularization and non-cardioembolic ischemic stroke was not reached, with no significant differences in these outcomes between the colchicine group compared to the placebo group.

The COLCHICINE-PCI trial [68], released in the first half of 2020, has provided rather disappointing results focusing on the role of this drug in the peri-interventional setting. The investigators showed that preprocedural administration of colchicine could have only a minor effect in reducing post-procedural inflammation, even though the trial yielded a formal negative result. This study randomized patients referred for possible PCI, who were given a colchicine loading dose of $1.2 \mathrm{mg}$ plus $0.6 \mathrm{mg}$ within 2 hours before PCI. The primary endpoint of PCI-related myocardial injury was the same between groups and no significant difference was observed in the composite outcome of death, MI and target revascularization at 30 days. Yet, the inflammatory biomarker substudy, proved that the increase in IL-6 and $\mathrm{hs}-\mathrm{CRP}$ at $24 \mathrm{~h}$ post-PCI was significantly reduced in the colchicine group, while this difference between treatment groups was not significant one hour after the procedure. A summary of major published trials on colchicine and its cardiovascular implications is shown in Table 4.

Furthermore, worrying findings have emerged from some of the major trials regarding non-cardiovascular risks of colchicine. In the COPS trial [64], an alarmingly higher rate of total death was observed in the colchicine group as compared to placebo. Similar results emerged in the LoDoCo2 trial [45], in which investigators state in the discussion of their manuscript that the observed non-significant incidence of non-CV death in the colchicine arm could have been due to chance, although an obtained hazard ratio of 1.51 is of potential concern. Nevertheless, a trend towards increased incidence of death from non- $\mathrm{CV}$ causes in the colchicine arm was present also in the two others main randomized clinical trials on the topic, COLCOT and LoDoCo2 thus suggesting a possible direct cause-effect relation between colchicine and non-CV death rather than a relation due to the play of chance. Importantly, it should be noted that none of the published RCTs were formally powered to address the outcome of non-CV death. To overcome this limitation, a recently published focused meta-analysis [69] pooled data from the main trials on the topic, showing a significant increase of non-CV death among colchicine-treated patients as compared to controls at an average follow-up of 25.1 months (OR $1.55,95 \%$ CI 1.10 to $2.17 ; p=0.010$ ). Moreover, a specific cause of death responsible for this excess of deaths has not been identified, underlining the need for further studies to shed light on the precise etiology and pathophysiological mechanisms supporting an unequivocal cause-effect relation between colchicine and non-CV deaths.

\section{Conclusions}

Considering the growing body of evidence obtained from RCT data, the use of colchicine demonstrated an effective reduction in ischemic events in patients with acute and chronic coronary syndromes while providing a favorable cost/benefit ratio, particularly when administered on top of the current optimal medical therapy. Downsides to its use are narrow therapeutic index, potential long-term toxicity, and notable drug-to-drug interactions. Furthermore, its net clinical benefit still needs to be unequivocally proven due to the signal of harm with respect to non-CV death. Such challenges would ultimately need to be tested in studies that will be powered for long-term efficacy and safety endpoints. To fully envision the use of colchicine in the treatment of ischemic heart disease, a major effort should be performed by personalizing its use in terms of timing, duration of treatment, and dose, reevaluating over time the net clinical benefit of this strategy by taking into account the underlying severity of CV disease, patient comorbidities and use of concomitant medications. Therefore, a specific biomarker or a combination of tools able to predict the response to colchicine treatment is still missing but could add information not available from the clinical assessment and help in the decision process regarding the use of this drug in clinical practice [70]

From these considerations, it arises the question about colchicine whether it is better to be loved rather than feared, or feared rather than loved, paraphrasing what Niccolò Machiavelli wrote in the Prince [71]. It might perhaps be answered: use with caution in a selected population of patients in which a net clinical benefit has been consistently proven. 


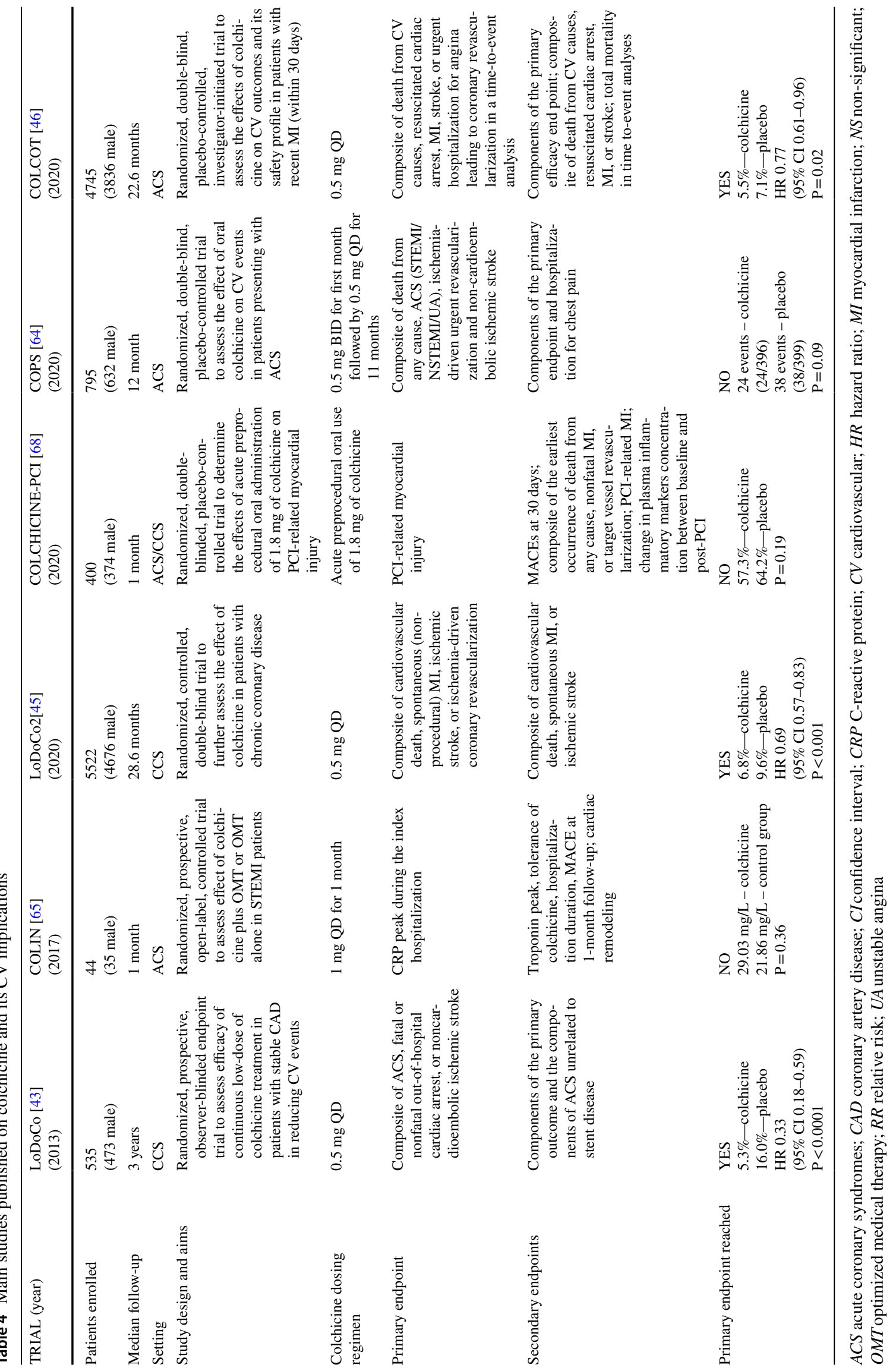


Acknowledgments A figure presented in this manuscript was created by the authors while some of the illustration elements were kindly provided by Servier. Servier Medical Art is licensed under a Creative Commons Attribution 3.0 Unported Licence.

Funding Open access funding provided by Università Cattolica del Sacro Cuore within the CRUI-CARE Agreement. This research did not receive any specific grant from funding agencies in the public, commercial, or not-for-profit sectors.

\section{Declarations}

Conflict of interest The authors have no conflict of interests or competing interests to declare with relation to the present manuscript.

Open Access This article is licensed under a Creative Commons Attribution 4.0 International License, which permits use, sharing, adaptation, distribution and reproduction in any medium or format, as long as you give appropriate credit to the original author(s) and the source, provide a link to the Creative Commons licence, and indicate if changes were made. The images or other third party material in this article are included in the article's Creative Commons licence, unless indicated otherwise in a credit line to the material. If material is not included in the article's Creative Commons licence and your intended use is not permitted by statutory regulation or exceeds the permitted use, you will need to obtain permission directly from the copyright holder. To view a copy of this licence, visit http://creativecommons.org/licenses/by/4.0/.

\section{References}

1. Raggi P, Genest J, Giles TJ, Rayner KJ, Dwivedi G, Beanlands RS, Gupta M (2018) Role of inflammation in the pathogenesis of atherosclerosis and therapeutic interventions. Atherosclerosis 276:98-108. https://doi.org/10.1016/j.atherosclerosis.2018.07.014

2. Liuzzo G, Biasucci LM, Gallimore JR, Grillo RL, Rebuzzi AG, Pepys MB, Maseri A (1994) The prognostic value of C-reactive protein and serum amyloid a protein in severe unstable angina. $\mathrm{N}$ Engl J Med 331(7):417-424. https://doi.org/10.1056/nejm199408 183310701

3. Bona RD, Liuzzo G, Pedicino D, Crea F (2011) Anti-inflammatory treatment of acute coronary syndromes. Curr Pharm Des 17(37):4172-4189. https://doi.org/10.2174/138161211798764771

4. Ridker PM, Everett BM, Thuren T et al (2017) Antiinflammatory therapy with canakinumab for atherosclerotic disease. N Engl J Med 377(12):1119-1131. https://doi.org/10.1056/nejmoa1707914

5. Biasucci LM, Pedicino D, Liuzzo G (2020) Promises and challenges of targeting inflammation to treat cardiovascular disease: the post-CANTOS era. Eur Heart J. 41(23):2164-2167. https:// doi.org/10.1093/eurheartj/ehz586

6. Sehested TSG, Bjerre J, Ku S, Chang A, Jahansouz A, Owens DK, Hlathy MA, Goldhaber-Fiebert JD (2019) Cost-effectiveness of Canakinumab for Prevention of Recurrent Cardiovascular Events. JAMA Cardiol 4(2):128-135. https://doi.org/10.1001/jamacardio. 2018.4566

7. Ridker PM (2020) From CANTOS to CIRT to COLCOT to Clinic: Will All Atherosclerosis Patients Soon Be Treated With Combination Lipid-Lowering and Inflammation-Inhibiting Agents? Circulation 141(10):787-789. https://doi.org/10.1161/circulatio naha.119.045256

8. Ridker PM, Everett BM, Pradhan A et al (2019) Low-dose methotrexate for the prevention of atherosclerotic events. N Engl J Med 380(8):752-762. https://doi.org/10.1056/nejmoa1809798
9. Lehrer-Graiwer J, Singh P, Abdelbaky A et al (2015) FDG-PET imaging for oxidized LDL in stable atherosclerotic disease: a phase II study of safety, tolerability, and anti-inflammatory activity. JACC Cardiovasc Imaging 8(4):493-494. https://doi.org/10. 1016/j.jcmg.2014.06.021

10. O'Donoghue ML, Braunwald E, White HD et al (2014) Effect of darapladib on major coronary events after an acute coronary syndrome: the SOLID-TIMI 52 randomized clinical trial. JAMA 312(10):1006-1015. https://doi.org/10.1001/jama.2014.11061

11. White HD et al (2014) (2014) Darapladib for preventing ischemic events in stable coronary heart disease. N Engl J Med 370:17021711. https://doi.org/10.1056/nejmoa1315878

12. O'Donoghue ML, Glaser R, Cavender MA et al (2016) Effect of Losmapimod on Cardiovascular Outcomes in Patients Hospitalized With Acute Myocardial Infarction: A Randomized Clinical Trial. JAMA 315(15):1591-1599. https://doi.org/10.1001/jama. 2016.3609

13. Nicholls SJ, Kastelein JJP, Schwartz GG et al (2014) Varespladib and cardiovascular events in patients with an acute coronary syndrome: the VISTA-16 randomized clinical trial. JAMA 311(3):252-262. https://doi.org/10.1001/jama.2013.282836

14. Kleveland O, Kunszt G, Bratlie M et al (2016) Effect of a single dose of the interleukin-6 receptor antagonist tocilizumab on inflammation and troponin $\mathrm{T}$ release in patients with non-STelevation myocardial infarction: a double-blind, randomized, placebo-controlled phase 2 trial. Eur Heart J 37(30):2406-2413. https://doi.org/10.1093/eurheartj/ehw171

15. US National Library of Medicine. ClinicalTrials.gov https://doi. org/10.1002/14651858.cd011047.pub2 (2016) .

16. LG Hemkens H Ewald VL Gloy et al 2016 Colchicine for prevention of cardiovascular events Cochrane Database Syst Rev https:// doi.org/10.1002/14651858.cd011047.pub2

17. Dasgeb B, Kornreich D, McGuinn K, Okon L, Brownell I, Sackett DL (2018) Colchicine: an ancient drug with novel applications. Br J Dermatol 178(2):350-356. https://doi.org/10.1111/bjd.15896

18. Hartung EF (1954) History of the use of colchicum and related medicaments in gout; with suggestions for further research. Ann Rheum Dis 13(3):190-200. https://doi.org/10.1136/ard.13.3.190

19. Karamanou M, Tsoucalas G, Pantos K, Androutsos G (2018) Isolating colchicine in 19th century: an old drug revisited. Curr Pharm Des 24(6):654-658. https://doi.org/10.2174/1381612824 666180115105850

20. Bhattacharyya B, Howard R, Maity SN, Brossi A, Sharma PN, Wolff $\mathrm{J}$ (1986) B ring regulation of colchicine binding kinetics and fluorescence. Proc Natl Acad Sci U S A 83(7):2052-2055. https://doi.org/10.1073/pnas.83.7.2052

21. Cortese F, Bhattacharyya B, Wolff J (1977) Podophyllotoxin as a probe for the colchicine binding site of tubulin. J Biol Chem 252(4):1134-1140

22. Wilson L (1970) Properties of colchicine binding protein from chick embryo brain Interactions with vinca alkaloids and podophyllotoxin. Biochemistry 9(25):4999-5007. https://doi.org/10. 1021/bi00827a026

23. Ray K, Bhattacharyya B, Biswas BB (1981) Role of B-ring of colchicine in its binding to tubulin. J Biol Chem 256(12):6241-6244

24. Pyles EA, Hastie SB (1993) Effect of the B ring and the C-7 substituent on the kinetics of colchicinoid-tubulin associations. Biochemistry 32(9):2329-2336. https://doi.org/10.1021/bi000 60a026

25. Chappey O, Scherrmann JM (1995) Colchicine: recent data on pharmacokinetics and clinical pharmacology. Rev Med Interne 16(10):782-789. https://doi.org/10.1016/0248-8663(96)80790-9

26. Slobodnick A, Shah B, Pillinger MH, Krasnokutsky S (2015) Colchicine: old and new. Am J Med 128(5):461-470. https://doi.org/ 10.1016/j.amjmed.2014.12.010 
27. Spiller HA. Colchicine in Encyclopedia of Toxicology, $1007-$ 1008, (Elsevier, 2014).

28. Niel E, Scherrmann J-M (2006) Colchicine today. Joint Bone Spine 73(6):672-678. https://doi.org/10.1016/j.jbspin.2006.03. 006

29. Khanna D, Khanna PP, Fitzgerald JD et al (2012) 2012 American College of Rheumatology guidelines for management of gout Part 2: therapy and antiinflammatory prophylaxis of acute gouty arthritis. Arthritis Care Res (Hoboken) 64(10):1447-1461. https://doi. org/10.1002/acr.21773

30. Dalbeth N, Lauterio TJ, Wolfe HR (2014) Mechanism of action of colchicine in the treatment of gout. Clin Ther 36(10):1465-1479. https://doi.org/10.1016/j.clinthera.2014.07.017

31. Andreu JM, Timasheff SN (1982) Tubulin bound to colchicine forms polymers different from microtubules. Proc Natl Acad Sci U S A 79(22):6753-6756. https://doi.org/10.1073/pnas.79.22.6753

32. Caviston JP, Holzbaur ELF (2006) Microtubule motors at the intersection of trafficking and transport. Trends Cell Biol 16(10):530-537. https://doi.org/10.1016/j.tcb.2006.08.002

33. Martillo MA, Nazzal L, Crittenden DB (2014) The crystallization of monosodium urate. Curr Rheumatol Rep 16(2):400. https://doi. org/10.1007/s11926-013-0400-9

34. Agudelo CA, Schumacher HR (1973) The synovitis of acute gouty arthritis A light and electron microscopic study. Hum Pathol 4(2):265-279. https://doi.org/10.1016/s0046-8177(73)80013-9

35. Ng G, Sharma K, Ward SM et al (2008) Receptor-independent, direct membrane binding leads to cell-surface lipid sorting and Syk kinase activation in dendritic cells. Immunity 29(5):807-818. https://doi.org/10.1016/j.immuni.2008.09.013

36. Landis RC, Yagnik DR, Florey O, Philippidis P, Emons V, Mason JC, Haskard DO (2002) Safe disposal of inflammatory monosodium urate monohydrate crystals by differentiated macrophages. Arthritis Rheum 46(11):3026-3033. https://doi.org/10.1002/art. 10614

37. Kingsbury SR, Conaghan PG, McDermott MF (2011) The role of the NLRP3 inflammasome in gout. J Inflamm Res 4:39-49. https://doi.org/10.2147/jir.s11330

38. Gaudry M, Roberge CJ, de Medicis R, Lussier A, Poubelle PE, Naccache PH (1993) Crystal-induced neutrophil activation. III. Inflammatory microcrystals induce a distinct pattern of tyrosine phosphorylation in human neutrophils. J Clin Invest 91(4):1649_ 1655. https://doi.org/10.1172/jci116373

39. Molad Y (2002) Update on colchicine and its mechanism of action. Curr Rheumatol Rep 4:252-256. https://doi.org/10.1007/ s11926-002-0073-2

40. Cronstein BN, Moland Y, Reibman J, Balakhane E, Levin RI, Weissmann G (1995) Colchicine alters the quantitative and qualitative display of selectins on endothelial cells and neutrophils. J Clin Invest 96(2):994-1002. https://doi.org/10.1172/jci118147

41. Thompson PL (2019) Colchicine in Cardiovascular Disease: Repurposing an Ancient Gout Drug. Clin Ther 41(1):8-10. https:// doi.org/10.1016/j.clinthera.2018.11.014

42. Casanova P, Artola RT, Mihos CG, Pineda AM, Santana O (2015) The cardiovascular effects of colchicine: a comprehensive review. Cardiol Rev 23(6):317-322. https://doi.org/10.1097/crd.00000 00000000056

43. Nidorf SM, Eikelboom JW, Budgeon CA, Thompson PL (2013) Low-dose colchicine for secondary prevention of cardiovascular disease. J Am Coll Cardiol 61(4):404-410. https://doi.org/10. 1016/j.jacc.2012.10.027

44. Nidorf SM, Fiolet ATL, Eikelboom JW et al (2019) The effect of low-dose colchicine in patients with stable coronary artery disease: The LoDoCo2 trial rationale, design, and baseline characteristics. Am Heart J. https://doi.org/10.1016/j.ahj.2019.09.011
45. Nidorf SM, Fiolet AT, Mosterd A et al (2020) Colchicine in patients with chronic coronary disease. N Engl J Med 383(19):1838-1847. https://doi.org/10.1056/nejmoa2021372

46. Bouabdallaoui N, Tardif JC, Waters DD et al (2020) 2020) Timeto-treatment initiation of colchicine and cardiovascular outcomes after myocardial infarction in the Colchicine Cardiovascular Outcomes Trial (COLCOT). Eur Heart J 41(42):4092-4099. https:// doi.org/10.1093/eurheartj/ehaa659

47. Samuel M, Tardif JC, Khairy P et al (2020) Cost-effectiveness of low-dose colchicine after myocardial infarction in the Colchicine Cardiovascular Outcomes Trial (COLCOT). Eur Heart J Qual Care Clin Outcomes. https://doi.org/10.1093/ehjqcco/qcaa045

48. Deftereos GG, Angelidis C et al (2015) Anti-Inflammatory Treatment With Colchicine in Acute Myocardial Infarction: A Pilot Study. Circulation 132(15):1395-1403. https://doi.org/10.1161/ circulationaha.115.017611

49. Vergallo R, Porto I, D'Amario D, et al (2019) Coronary atherosclerotic phenotype and plaque healing in patients with recurrent acute coronary syndromes compared with patients with long-term clinical stability: an in vivo optical coherence tomography study. JAMA Cardiol. 4(4):321-329. https://doi.org/10.1001/jamacardio. 2019.0275

50. Vergallo R, Crea F (2020) Atherosclerotic Plaque Healing. N Engl J Med 383(9):846-857. https://doi.org/10.1056/nejmra2000317

51. Vaidya K, Arnott C, Martínez GJ, Ng B, McCormak S, Sullivan DR, Celermajer DS, Patel S (2018) Colchicine therapy and plaque stabilization in patients with acute coronary syndrome: a CT coronary angiography study. JACC Cardiovasc Imaging 11:305-316. https://doi.org/10.1016/j.jcmg.2017.08.013

52. Flego D, Liuzzo G, Weyand CM, Crea F (2016) Adaptive immunity dysregulation in acute coronary syndromes: from cellular and molecular basis to clinical implications. J Am Coll Cardiol 68(19):2107-2117. https://doi.org/10.1016/j.jacc.2016.08.036

53. Basile U, La Rosa G, Napodano C, Pocino K, Cappannoli L, Gulli F, Cianfrocca C, Di Stasio E, Biasucci LM (2019) Free light chains a novel biomarker of cardiovascular disease. A pilot study. Rev Med Pharmacol Sci 23(6):2563-2569. Doi: https:// doi.org/10.26355/eurrev_201903_17405

54. Vaidya K, Tucker B, Kurup R et al (2020) Colchicine inhibits neutrophil extracellular trap formation in patients with acute coronary syndrome after percutaneous coronary intervention. J Am Heart Assoc 21:e018993. https://doi.org/10.1161/JAHA. 120.018993

55. Pedicino D, Severino A, Ucci S et al (2017) Epicardial adipose tissue microbial colonization and inflammasome activation in acute coronary syndrome. Int J Cardiol 1(236):95-99. https://doi.org/ 10.1016/j.ijcard.2017.02.040

56. Martínez GJ, Robertson S, Barraclough J, Xia Q, Mallat Z, Bursill C, Celermajer DS, Patel S (2015) Colchicine Acutely Suppresses Local Cardiac Production of Inflammatory Cytokines in Patients With an Acute Coronary Syndrome. J Am Heart Assoc 4(8):e002128. https://doi.org/10.1161/jaha.115.002128

57. Robertson S, Martinez GJ, Payet CA, Barraclough JY, Celermajer DS, Bursill C, Patel S (2016) Colchicine therapy in acute coronary syndrome patients acts on caspase-1 to suppress NLRP3 inflammasome monocyte activation. Clin Sci (Lond) 130(14):12371246. https://doi.org/10.1042/cs20160090

58. Tucker B, Kurup R, Barraclough J et al (2019) Colchicine as a Novel Therapy for Suppressing Chemokine Production in Patients With an Acute Coronary Syndrome: A Pilot Study. Clin Ther 41(10):2172-2181. https://doi.org/10.1016/j.clinthera.2019.07. 015

59. Stone GW, Selker HP, Thiele H et al (2016) Relationship Between Infarct Size and Outcomes Following Primary PCI: Patient-Level 
Analysis From 10 Randomized Trials. J Am Coll Cardiol 67(14):1674-1683. https://doi.org/10.1016/j.jacc.2016.01.069

60. US National Library of Medicine. ClinicalTrials.gov https://clini caltrials.gov/ct2/show/NCT03048825(2017).

61. US National Library of Medicine. ClinicalTrials.gov https://clini caltrials.gov/ct2/show/record/NCT03874338 (2019).

62. US National Library of Medicine. ClinicalTrials.gov https://clini caltrials.gov/ct2/show/NCT03156816 (2017).

63. Deftereos S, Giannopoulos G, Panagopolou V et al (2014) Anti-inflammatory treatment with colchicine in stable chronic heart failure: a prospective, randomized study. JACC Heart Fail 2(2):131-137. https://doi.org/10.1016/j.jchf.2013.11.006

64. Tong DC, Quinn S, Nasis A et al (2020) Colchicine in patients with acute coronary syndrome: the australian cops randomized clinical trial. Circulation 142(20):1890-1900. https://doi.org/10. 1161/circulationaha.120.050771

65. Akodad M, Lattuca B, Nagot N et al (2017) COLIN trial: Value of colchicine in the treatment of patients with acute myocardial infarction and inflammatory response. Arch Cardiovasc Dis 110(6-7):395-402. https://doi.org/10.1016/j.acvd.2016.10.004

66. Fernández-Cuadros ME, Goizueta-San-Martin G, Varas-de-Dios B et al (2019) Colchicine-Induced Rhabdomyolysis: Clinical, Biochemical, and Neurophysiological Features and Review of the Literature. Clin Med Insights Arthritis Musculoskelet Disord 12:1179544119849883. https://doi.org/10.1177/1179544119 849883

67. McKnight AH, Katzenberger DR, Britnell SR (2021) Colchicine in acute coronary syndrome: a systematic review. Ann Pharmacother 55(2):187-197. https://doi.org/10.1177/1060028020942144

68. Shah B, Pillinger M, Zhong H et al (2020) Effects of Acute Colchicine Administration Prior to Percutaneous Coronary Intervention:
COLCHICINE-PCI Randomized Trial. Circ Cardiovasc Interv 13(20):e008717. https://doi.org/10.1161/circinterventions.119. 008717

69. Galli M, Princi G, Crea F, D'Amario D (2020) Colchicine and risk of non-cardiovascular death in patients with coronary artery disease: a pooled analysis underlining possible safety concerns. Eur Heart J Cardiovasc Pharmacother. https://doi.org/10.1093/ ehjcvp/pvaa137

70. Crea F, Liuzzo G (2018) Addressing acute coronary syndromes: new challenges and opportunities after the CANTOS Trial (Canakinumab Anti-inflammatory Thrombosis Outcomes Study). Circulation 137(11):1100-1102. https://doi.org/10.1161/circulatio naha.117.032178

71. Machiavelli N. in The Prince (Chapter XVII: Concerning Cruelty: Whether It Is Better to Be Loved Than to Be Feared, or the Reverse). 1513.

72. Kuncl RW, Duncan G, Watson D, Alderson K, Rogawski MA, Peper M (1987) Colchicine Myopathy and Neuropathy. N Engl J Med 316(25):1562-1568. https://doi.org/10.1056/nejm198706 183162502

73. McKinnell J, Tayek JA (2009) Short term treatment with clarithromycin resulting in colchicine-induced rhabdomyolysis. J Clin Rheumatol 15(6):303-305. https://doi.org/10.1097/rhu.0b013 e3181bbbcd7

74. Tateishi T, Soucek P, Caraco Y, Guengerich FP, Wood AJ (1997) Colchicine biotransformation by human liver microsomes Identification of CYP3A4 as the major isoform responsible for colchicine demethylation. Biochem Pharmacol 53(1):111-116. https://doi. org/10.1016/s0006-2952(96)00693-4 